\title{
Perancangan Prototipe Kapal Remote Control Pemberi Pakan pada Budidaya Benih Ikan Mas Berkapasitas Muatan 2 kg Menggunakan Metode Perbandingan dengan Skala 1:25
}

\author{
Kasda*, Susanto, Ari Aji Bekti \\ Fakultas Teknik, Universitas Subang \\ Jalan Arief Rahman Hakim No.8 Subang, Jawa Barat \\ *E-mail: kasdaft@unsub.ac.id
}

Diterima: 02-12-2020; Direvisi: 10-03-2021; Dipublikasi: 27-04-2021

\begin{abstract}
Abstrak
Pemberian pakan dengan cara ditabur secara manual oleh orang sambil berjalan mengelilingi kolam untuk mendekati gerombolan ikan, menjadi tidak efektif karena dapat menguras waktu dan tenaga terutama bagi pembudidaya yang memiliki banyak kolam. Perancangan prototipe kapal remote control pemberi pakan dilakukann untuk memberikan solusi dalam meningkatkan efektifitas dan efisiensi proses pemberian pakan pada benih ikan usia 11-18 hari. Sebagai tahap awal penelitian, proses perancangan dilakukan untuk menentukan ukuran utama prototipe kapal yang dapat mambawa muatan maksimum pakan sebear $2 \mathrm{~kg}$ dan kecepatan operasi sebesar $0,81 \mathrm{~m} / \mathrm{s}$. Dari hasil perancangan dengan metoda perbandingan (skala 1:25) dan beberapa langkah modifikasi didapat ukuran utama kapal yaitu $\mathrm{L}=0,7 \mathrm{~m}$, $\mathrm{B}=0,22 \mathrm{~m}, \mathrm{H}=0,1 \mathrm{~m}$ dan $\mathrm{T}=0,05, \mathrm{Cb}=0,66$ dengan displacement sebesar 5,67 kg. Hambatan kapal dihitung menggunakan metode holtrop. Pada kecepatan operasi kapal sebesar $0,81 \mathrm{~m} / \mathrm{s}$ didapat hambatan sebesar $0,337 \mathrm{~N}$. Dengan demikian efektif daya (EHP) dapat ditentukan sebesar 0,237 watt.
\end{abstract}

Kata kunci: Hambatan; Ikan; Kecepatan; Kapal.

\begin{abstract}
Manual feeding by people while walking around the pond to approach the fish collection is ineffective because it can drain time and energy, especially for farmers who have many ponds. The design of the remote control feeder ship prototype was carried out to provide a solution in increasing the effectiveness and efficiency of the feeding process for fish seeds aged 11-18 days. As the initial stage of the research, the design process was carried out to determine the main size of the ship prototype ship which can load a maximum feed of $2 \mathrm{~kg}$ and an operating speed of $0.81 \mathrm{~m} / \mathrm{s}$. From the design results with the comparison method (scale 1:25) and several modification steps, the main size of the ship prototype are $L=0.7 \mathrm{~m}, B=0.22 \mathrm{~m}, \mathrm{H}=0.1 \mathrm{~m}$ and $T=0.05, \mathrm{Cb}=0.66$, with a displacement of $5.67 \mathrm{~kg}$. . The ship resistance is calculated using the holtrop method. At the ship's operating speed of $0.81 \mathrm{~m} / \mathrm{s}$, the resistance is $0.337 \mathrm{~N}$. Thus the effective power (EHP) can be determined to be 0.237 watts.
\end{abstract}

Keywords: Fish; Resistance; Ship;Velocity.

\section{Pendahuluan}

Ikan mas merupakan salah satu jenis ikan yang mempunyai nilai ekonomis tinggi dan banyak dibudidayakan karena mempunyai daya adaptasi yang tinggi terhadap kondisi lingkungan dan makanan yang tersedia [1]. Pemberian pakan merupakan salah satu hal penting untuk usaha budidaya ikan. Saat ini pemberian pakan umumnya masih tergantung pada sumber daya manusia yang bersifat manual [2]. Salah satu sarana penunjang budidaya adalah alat penebar pakan ikan yang telah diaplikasikan [3]. Dengan menggunakan kapal tanpa awak penebar pakan ikan berbasis microcontroller Arduino pemberian pakan ikan akan lebih mudah, efisien, dan merata [4]. Diharapkan dengan peralatan ini dapat menjadi solusi yang tepat para pembudidaya dalam proses pemberian pakan ikan dengan mudah dan efisien [5].

Cara pemberian pakan pada budidaya benih ikan mas diwilayah Pabuaran Kabupaten Subang, terdiri dari 4 (empat) fase berdasarkan usia benih ikan. Fase kedua pemberian pakan benih ikan mas usia 11-18 hari dengan cara pakan ditabur secara manual oleh orang sambil berjalan mengelilingi kolam untuk mendekati gerombolan ikan disekitar pinggir tanggul kolam. Jenis pakan yang diberikan pada fase kedua ini berupa pakan halus. Banyaknya pakan halus yang ditabur untuk sekali memberi makan berkisar antara 1-2 kg dengan waktu tabur sekitar 5-10 menit. 
Luas satu kolam benih ikan mas rata-rata sekitar $3.000 \mathrm{~m}^{2}$ dengan kelililing kolam sekitar $220 \mathrm{~m}$. Dengan demikian cara pemberian pakan sambil berjalan mengelilingi kolam menjadi kurang efektif karena menguras waktu dan tenaga, terutama bagi pembudidaya yang memiliki kolam ikan lebih dari satu kolam. Untuk menjawab permasalahan ini sebuah gagasan untuk merancang prototipe kapal remote kontrol pemberi pakan untuk usia benih ikan mas 11-18 hari yang mampu membawa muatan pakan maksimum $2 \mathrm{~kg}$ untuk sekali trip. Pengujian fungsi wadah pakan (hopper) pengumpan sistem gravitasi menunjukkan hasil bahwa $1 \mathrm{~kg}$ pakan dapat ditabur sampai habis dengan waktu 137 detik [6]. Sehingga untuk menabur pakan sebanyak $2 \mathrm{~kg}$ perlu waktu sekitar 274 detik. Dengan demikian untuk jarak tempuh satu kali trip sekitar 220 meter, maka kecepatan kapal dirancang memiliki kecepatan operasi sebesar 0,81 m/s. Karena prototipe kapal remote control pemberi pakan ini rencananya akan menggunakan penggerak motor DC, dimana energinya disuplai dari batere penyimpan daya yang dapat diisi ulang, sehingga penggunaannya harus sehemat mungkin, maka perlu dilakukan perhitungan hambatan kapal, sebagai dasar untuk menentukan daya efektif (EHP).

Berlatar belakang permasalahan di atas, penelitian awal ini bertujuan untuk merancang bentuk dan ukuran utama prototipe kapal remote kontrol pemberi pakan pada budi daya benih ikan mas usia 11-18 hari, yang dapat membawa muatan pakan maksimum sebanyak $2 \mathrm{~kg}$ dengan kecepatan operasi sebesar $0,81 \mathrm{~m} / \mathrm{s}$. Jenis pakan untuk usia benih ikan 11-18 hari berupa pakan serbuk halus. Penelitian sebelumnya telah dilakukan pembuatan kapal remote kontrol dengan biaya pembuatan yang murah dan berkapasitas muatan sebanyak $1 \mathrm{~kg}$ dengan kecepatan operasi kapal sebesar 0,5 m/s, berhasil menabur pakan secara otomatis dengan sistem pengumpanan pakan secara gravitasi. Kapal remote kontrol ini khusus dirancang untuk memberi pakan pada benih ikan usia 25- 45 hari dengan ukuran pakan berdiameter $3 \mathrm{~mm}$ [7]. Untuk memenuhi rancangan kecepatan operasi kapal, maka perhitungan hambatan kapal harus dilakukan sebagai dasar dalam menentukan besar daya efeketif kapal agar kapal dapat bergerak sesuai kecepatan operasi. Motode holtrop merupakan metode perhitungan hambatan kapal dengan menggunakan formula pendakatan matematis [8]. Hambatan kapal yang memiliki kecepatan rendah hingga sedang, cocok dihitung dengan menggunakan metode harvald, dan untuk kapal dengan kecepatan tinggi, maka hambatannya lebih cocok dihitung menggunakan metode Holtrop karena menghasilkan hambatan yang lebih rendah [9].

\section{Material dan metodologi}

\subsection{Lokasi Penelitian}

Data awal penelitian didapat dari hasil survey, wawancara dan diskusi dengan pembudidaya benih ikan mas di Dusun Cinangka Desa Salamjaya Kecamatan Pabuaran Kabupaten Subang Jawa Barat.

\subsection{Tahapan Perancangan}

\section{Model dan Ukuran Utama Kapal}

Dalam proses perancangan kapal, salah satu faktor yang cukup signifikan untuk dipertimbangkan adalah penetapan metode rancangan sebagai salah satu upaya untuk menghasilkan output rancangan yang optimal dan memenuhi berbagai kriteria yang disyaratkan. Metode yang digunakan dalam perancangan ini adalah menggunakan Metode Perbandingan (comparasion method) [10]. Dalam desain sebuah kapal, karakteristik perbandingan merupakan hal penting yang harus diperhatikan. Perbandingan tersebut meliputi perbandingan antara panjang dan lebar (L/B), perbandingan antara lebar dan Sarat $(\mathrm{B} / \mathrm{T})$, perbandingan antara panjang dan tinggi $(\mathrm{L} / \mathrm{H})[11]$. Metoda perbandingan ini mensyaratkan adanya satu kapal pembanding dengan tipe yang sama dan telah memenuhi criteria. Ukuran-ukuran pokok kapal dihasilkan dengan cara mengalikan ukuran pokok kapal pembanding dengan faktor skala (scale). 
Perancangan dimulai dengan menentukan bentuk dan ukuran utama kapal berdasarkan keperluan bahwa kapal harus mampu membawa muatan pakan maksimum $2 \mathrm{~kg}$. Ukuran kapal yang menjadi pembanding adalah kapal tongkang (Barge) seperti terlihat pada

Tabel 1. Tongkang adalah suatu jenis kapal dengan lambung datar atau suatu kotak besar yang mengapung, digunakan untuk mengangkut barang [12]. Tahapan perancangan dan pemilihan bentuk dan penentuan ukuran utama prototipe kapal remote kontrol pemberi pakan, dengan metoda perbandingan merujuk pada kapal barge tipe $15 \mathrm{M}$ Workboat sebagaimana dapat dilihat pada

Tabel 1 dengan skala perbandingan $1: 25$.

Tabel 1. Data Teknis Kapal Pembanding (Barges) [10]

\begin{tabular}{lccccc}
\hline \multicolumn{1}{c}{ Barges } & LWL $(\mathbf{m})$ & B(m) & T(m) & H(m) & Muatan (Ton) \\
\hline 11,75 Metre Landing Barge & 11,75 & 4,00 & 0,45 & 0,80 & 20,00 \\
12 m High Speed Barge & 11,90 & 5,70 & 0,60 & 1,70 & 32,00 \\
12 Metre Work Barge 1 & 11,90 & 6,00 & 0,80 & 1,10 & 37,50 \\
12M Work Barge 2 & 11,90 & 5,40 & 0,66 & 1,00 & 20,00 \\
15m Workboat & 15,00 & 6,00 & 1,35 & 2,40 & 100,00 \\
\hline
\end{tabular}

Setelah ukuran utama prototipe kapal ditentukan, maka volume displacement $(\nabla)$ dapat dihitung dengan mengalikan panjang garis air kapal /Length Water Line (LWL), lebar kapal / Beam (B), Sarat kapal / Draft (T) dan Coefisien Block (Cb) menggunakan Pers. (1).

$$
\nabla=L W L \times B \times T \times C b
$$

Sementara berat displacement $(\Delta)$ adalah sama dengan total volume air yang dipindahkan sebagai gaya angkat ke atas (Hukum Archimedes) dimana besarnya gaya angkat dapat ditentukan dengan mengalikan volume displacement $(\nabla)$ dengan massa jenis air ( $\rho)$ seperti pada Pers. (2).

$$
\Delta=\nabla x \rho
$$

\section{Penampung Pakan}

Penampung pakan dirancang untuk dapat menampung pakan sebanyak $2 \mathrm{~kg}$ tanpa mengalami tumpah serta dengan pertimbangan bahwa dimensinya harus menyesuaikan dengan ukuran utama kapal. Untuk menentukan ukuran penampung pakan, maka berat pakan sebesar $2 \mathrm{~kg}$ harus dikonversi ke dalam volume terlebih dahulu. Nilai densitas hasil penelitian tidak jauh berbeda dengan nilai densitas pakan ikan produksi pabrik, dimana rata-rata nilai densitas hasil pengukuran pelet ikan adalah sebesar $460 \mathrm{~kg} / \mathrm{m}^{3}$ [13]. Dengan demikian volume pakan dapat dihitung dengan membagi massa pakan (m) dengan massa jenis pakan ( $\rho$ pakan) seperti Pers. (3). Agar penampung pakan dapat berfungsi dengan baik tanpa mengalami tumpah terutama pada saat muatannya maksimum, maka perancangan volume penampung pakan harus lebih besar dari volume maksimum pakan. Oleh karena itu volume maksimum pakan dapat diasumsikan sama dengan $3 / 4$ volume penampung, sehingga volumenya dapat dihitung dengan Pers. (4). Dengan demikian ukuran hoper dapat ditentukan dengan Pers. (5). 


$$
\begin{aligned}
& \mathrm{v}_{\text {pakan }}=\frac{m}{\rho_{\text {pakan }}} \\
& \mathrm{v}_{\text {hopper }}=\frac{4}{3} \mathrm{v}_{\text {pakan }} \\
& \mathrm{v}_{\text {hopper }}=p \times l \times t
\end{aligned}
$$

\section{Hambatan Kapal}

Proses pengiriman barang/muatan dengan kapal tongkang banyak dijumpai karena kemudahan aksesnya dimana kapal tongkang memiliki sarat air (draft) yang lebih kecil dibandingkan dengan jenis kapal lain. Penelitian ini mencoba menentukan hambatan pada kapal tanpa awak berbentuk kapal tongkang untuk beberapa kecepatan [14]. Ada Tiga jenis hambatan yang harus diperhitungkan pada hambatan kapal yaitu hambatan gesekan, hambatan tekanan kental, dan hambatan gelombang [15].

Perhitungan hambatan kapal pada prototipe kapal remote kontrol pada penelitian ini akan lebih disederhanakan hanya pada perhitungan hambatan akibat gesekan fluida cair dan hambatan akibat gesekan udara. Untuk perhitungan hambatan akibat gelombang tidak akan dilakukan dengan asumsi karena kapal akan dioperasikan pada perairan tenang (kolam ikan) kemudian untuk hambatan sisa lainnya, perhitungannya tidak mungkin dilakukan karena kurangnya informasi dan data tambahan dari kapal pembanding. Sehingga hambatan total sama dengan hambatan fluida cair ditambah hambatan gesek fluida udara. Hambatan akibat gesekan fluida cair $\left(R_{f}\right)$ dan akibat gesekan fluida udara $\left(R_{A}\right)$ sebagaimana dapat dihitung dengan Pers.(6-10), sementara hambatan total kapal dapat dihitung dengan Pers. (11).

$$
\begin{aligned}
& R_{f}=\frac{1}{2} \times \rho \times C_{f} \times s \times V^{2} \\
& C_{f}=\frac{0,075}{(\log R e-2)^{2}} \\
& R e=\frac{V \times L}{v} \\
& S=1,025 \times L W L \times\left(C_{b} \times B \times 1,7 T\right) \\
& R_{A}=\frac{1}{2} C_{A} \times \rho_{A} \times A_{T} \times V^{2}
\end{aligned}
$$

dimana $C_{f}=$ koefisien hambatan gesek, $\rho=$ massa jenis fluida $\left(\mathrm{kg} / \mathrm{m}^{3}\right), \mathrm{s}=$ luas permukaan basah $\mathrm{kapal}\left(\mathrm{m}^{2}\right), \mathrm{V}=$ kecepatan operasi kapal (m/s), Re= Bilangan Reynold, $\mathrm{LWL}=$ Panjang garis ir kapal, $v=$ viskositas kinematik fluida, $C_{A}=$ koefisien bentuk penampang hambatan, $\rho_{A}=$ massa jenis udara $\left(\mathrm{kg} / \mathrm{m}^{3}\right), \mathrm{A}_{\mathrm{T}}=$ luas penampang transversal bagian atas kapal $\left(\mathrm{m}^{2}\right)$. Sehingga hambatan total kapal sesuai dengan Pers. (11).

$$
R_{T}=R_{f}+R_{A}
$$

\section{Daya Efektif (EHP)}

Setelah hambatan total didapat, makan langkah selanjutnya adalah menghitung daya efektif kapal (EHP) dengan cara mengalikan hambatan total $\left(\mathrm{R}_{\mathrm{T}}\right)$ dengan kecepatan operasi kapal (V). Daya efektif atau EHP adalah daya yang diperlukan untuk menggerakkan kapal di air atau untuk menarik kapal dengan kecepatan v.

$$
E H P=R_{T} \times V
$$

\section{Hasil dan pembahasan}


Hasil dari skala perbandingan maka perancangan ukuran utama prototype kapal remote kontrol dapat ditentukan sebagaimana dapat dilihat pada Tabel 2. Untuk memeriksa bahwa ukuran utama prototipe kapal sudah sesuai dengan acuan perbandingan ukuran utama kapal untuk kapal-kapal motor kecil ditetapkan yaitu untuk perbandingan L/B, T/B, H/B, T/H dan L/H [16]. Hasil yang diperlihatkan pada Tabel 3 menunjukan bahwa perbandingan ukuran utama prototipe kapal remote kontrol masih belum belum sesuai dengan perbandingan acuan. Untuk itu dilakukan modifikasi perubahan ukuran utama prototipe kapal sampai perbandingan ukuran utamanya sesuai dengan kriteria perbandingan acuan.

Tabel 2. Ukuran Utama Prototipe Kapal Remote Kontrol

\begin{tabular}{cccccc}
\hline Barges & L (m) & B(m) & T(m) & H(m) & Muatan (kg) \\
\hline Prototipe Kapal Remote Kontrol & 0,6 & 0,24 & 0,054 & 0,092 & 2 \\
\hline
\end{tabular}

Tabel 3. Perbandingan ukuran utama kapal awal

\begin{tabular}{cccc}
\hline Perbandingan & Prototipe Kapal & Kapal Motor Kecil & Keterangan \\
\hline L/B & 2,50 & $3,20-6,30$ & $\times$ \\
T/B & 0,23 & $0,30-0,50$ & $\times$ \\
B/H & 2,67 & $1,73-2,20$ & $\times$ \\
T/H & 0,60 & $0,30-0,60$ & $\sqrt{ }$ \\
L/H & 6,67 & $6,00-11,00$ & $\sqrt{ }$ \\
Cb & 0,66 & $0,50-0,66$ & $\sqrt{ }$ \\
\hline
\end{tabular}

Tabel 4 dan Tabel 5, memperlihatkan hasil modifikasi ukuran utama prototipe kapal remote control dan hasil perbandingan ukuran utama yang sudah sesuai dengan perbandingan acuan untuk kapal motor kecil. Untuk menampung pakan $2 \mathrm{~kg}$ dengan volume $0,006 \mathrm{~m}^{3}$, maka wadah penampung pakan dapat ditentukan memiliki luas penampang sebesar $0,35 \times 0,16 \mathrm{~m}^{2}$ dengan tinggi $0,10 \mathrm{~m}$. Adapun bentuk dari prototipe sebagaimana dapat dilihat pada Gambar 2.

Tabel 4. Ukuran utama Prototipe Kapal Remote Control hasil modifikasi

\begin{tabular}{cccccc}
\hline Barges & L (m) & B(m) & T(m) & H(m) & Muatan (kg) \\
\hline Prototipe Kapal Remote Kontrol & 0,70 & 0,22 & 0,05 & 0,11 & 2 \\
\hline
\end{tabular}

Tabel 5. Perbandingan ukuran utama kapal hasil modifikasi

\begin{tabular}{cccc}
\hline Perbandingan & Prototipe Kapal & Kapal Motor Kecil & Keterangan \\
\hline L/B & 3,18 & $3,20-6,30$ & $\sqrt{ }$ \\
T/B & 0,25 & $0,30-0,50$ & $\sqrt{ }$ \\
B/H & 2,06 & $1,73-2,20$ & $\sqrt{ }$ \\
T/H & 0,50 & $0,30-0,60$ & $\sqrt{ }$ \\
L/H & 6,54 & $6,00-11,00$ & $\sqrt{ }$ \\
Cb & 0,66 & $0,50-0,66$ & $\sqrt{ }$ \\
\hline
\end{tabular}

Untuk menghitung hambatan total, beberapa data teknis yang diperlukan sebelumnya sudah dihitung dan mendapatkan hasil hitungan sebagaimana dapat dilihat pada 
Tabel 6. Hambatan total kapal dihitung dengan variasi kecepatan kapal mulai 0 m/s sampai dengan kecepatan operasi maksimum sebesar $0,81 \mathrm{~m} / \mathrm{s}$ dan hasil grafik kecepatan versus hambatan sebagaimana dapat dilihat pada Gambar 2 . Dimana semakin besar kecepatan kapal maka hambatan besar pula hambatan kapal. Pada posisi kecepatan operasi kapal sebesar $0,81 \mathrm{~m} / \mathrm{s}$, hambatan total $\left(\mathrm{R}_{\mathrm{T}}\right.$ ) yang terjadi sebesar $0,337 \mathrm{~N}$. Dengan demikian pada kecepatan operasi $0,81 \mathrm{~m} / \mathrm{s}$ dengan menggunakan Pers. (12) diperoleh daya efektif kapal 0,273 watt.

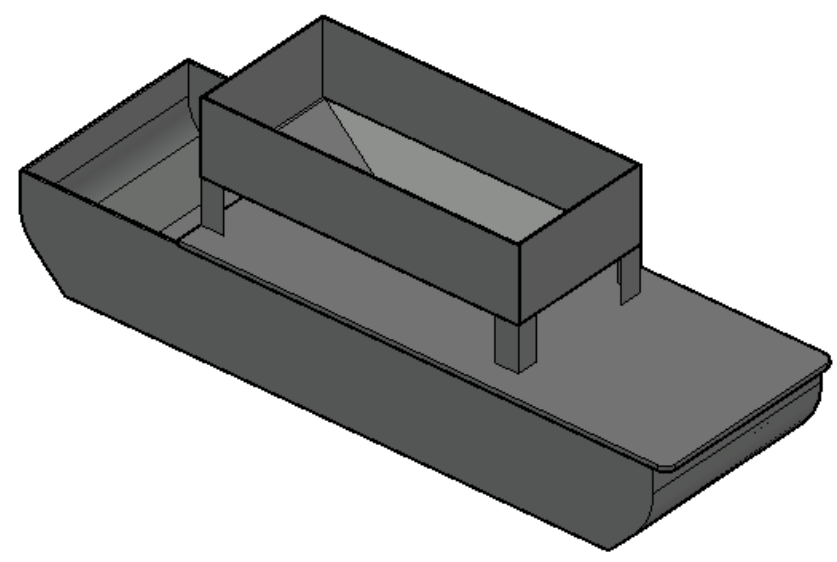

Gambar 1. Model prototipe kapal remote control

Tabel 6. Data teknis untuk perhitungan hambatan total

\begin{tabular}{llrc}
\hline \multicolumn{1}{c}{ Uaian } & Simbol & Nilai & Satuan \\
\hline Massa jenis air & $\rho$ & $1.000,00$ & $\mathrm{~kg} / \mathrm{m}^{3}$ \\
Koefisien kekentalan kinematis & $\mathrm{V}$ & $1,1883 \mathrm{E}-06$ & $\mathrm{~m}^{2} / \mathrm{s}$ \\
Panjang Kapal & $\mathrm{L}$ & 0,70 & $\mathrm{~m}$ \\
Bilangan Reynold & $\mathrm{Re}$ & 471.261 & \\
& $\mathrm{Log}(\mathrm{Re})$ & 5,67326193 & \\
Koefisien hambatan gesek & $\mathrm{C}_{\mathrm{f}}$ & 0,0055585 & \\
Luas permukaan basah lambung kapal & $\mathrm{S}$ & 0,1700475 & $\mathrm{~m}^{2}$ \\
Massa Jenis udara & $\rho_{\text {udara }}$ & 1,12 & $\mathrm{~kg} / \mathrm{m}^{3}$ \\
Luas proyeksi transfersal bagian atas air kapal & $\mathrm{A}_{\mathrm{T}}$ & 0,04086551 & $\mathrm{~m}^{2}$ \\
Koefisien bentuk permukaan & $\mathrm{C}_{\mathrm{A}}$ & 1,3 & \\
\hline
\end{tabular}

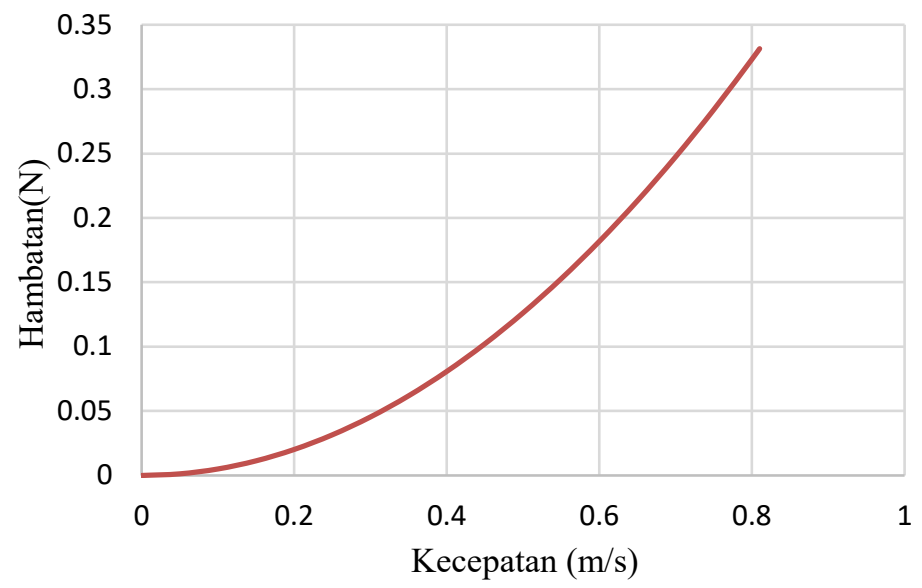

Gambar 2. Grafik Kecepatan Vs Hambatan 


\section{Kesimpulan}

Hasil proses perancangan bentuk dan ukuran utama prototype kapal remote control dengan metoda perbandingan dengan skala 1:25, maka dapat dipilih jenis kapal muatan tongkang dengan ukuran utama kapal yaitu $\mathrm{L}=0,70 \mathrm{~m}, \mathrm{~B}=0,22 \mathrm{~m}$, $\mathrm{H}=0,11 \mathrm{~m}, \mathrm{~T}=0,05 \mathrm{~m}$ dengan $\mathrm{Cb}=0,66$ serta berat displacement sebesar 5,67 kg. Perhitungan hambatan kapal dengan metoda holtrop, didapatkan nilai hambatan total kapal sebesar $0,337 \mathrm{~N}$ sehingga daya efeketif kapal dapat ditentukan sebesar 0,22 watt. Untuk memvalidasi keberhasilan perhitungan dan proses perancangan prototipe kapal di atas, maka untuk penelitian selanjutnya akan dilakukan perancangan pemilihan sistem penggerak, pembuatan dan pengujian fungsi dari prototipe kapal.

\section{Ucapan Terima Kasih}

Ucapan terima kasih yang sebesar-besarnya kepada Direktorat Riset dan Pengabdian Masyarakat Kementrian Riset dan Teknologi-Badan Riset dan Inovasi Nasional sebagai Sponsor Hibah Penelitian Tahun 2020.

\section{Daftar Pustaka}

[1] A. Mustofa, S. Hastuti, and D. Rachmawati, "PENGARUH PERIODE PEMUASAAN TERHADAP EFISIENSI PEMANFAATAN PAKAN, PERTUMBUHAN DAN KELULUSHIDUPAN IKAN MAS (Cyprinus carpio),” Pena Akuatika J. Ilm. Perikan. dan Kelaut., 2018, doi: 10.31941/penaakuatika.v17i2.705.

[2] A. Ardiwijoyo and A. M. Mappalotteng, "Rancang Bangun Alat Pemberi Pakan Ikan dengan Sistem Automatisasi Berbasis Arduino Uno R3 dengan Sistem Kendali SMS,” J. Pendidik. Teknol. Pertan., vol. 4, pp. 12-20, 2020.

[3] R.A. WIBISONO, "RANCANG BANGUN ALAT PENEBAR PAKAN IKAN DENGAN MENGGUNAKAN GAYA SENTRIFUGAL TIPE APUNG,” 2018.

[4] A.S. Dabit, "Perancangan Kapal Tanpa Awak Penebar Pakan Ikan di Wilayah Pesisir Pantai Berbasis Microcontroller Arduino,” Mek. Maj. Ilm. Mek., 2020, doi: 10.20961/mekanika.v19i2.43671.

[5] H. Yenni and B. Benny, "Perangkat Pemberi Pakan Otomatis Pada Kolam Budidaya," J. Process., vol. 11, no. 2, pp. 772-782, 2017.

[6] Maulana Rachman, "RANCANG BANGUN REMOTE CONTROL BARGE BOAT UNTUK FEEDER FLOATING FOOD POND DENGAN MUATAN 1 KG,” Subang, 2019.

[7] M. R. Kasda, Deny Poniman Kosasih, Hari Din Nugraha*, "Low Cost Remote Control Barge Boat to Feeder Fish," J. Mech. Eng. Res. Dev., vol. 44, no. 2, pp. 112-121, 2021.

[8] E. Sugianto and A. Winarno, "COMPUTATIONAL MODEL TAHANAN KAPAL UNTUK MENENTUKAN KEBUTUHAN DAYA KAPAL BULK CARRIER 8664 DWT,” J. Kelaut. Indones. J. Mar. Sci. Technol., 2018, doi: $10.21107 / \mathrm{jk} . v 10 \mathrm{i} 2.3411$.

[9] Gusma, “Tugas Perancangan Sistem Propeller dan Perporosan,” Surabaya, 2012. [Online]. Available: https://caridokumen.com/download/4212100007-gusma-tugas-perancangan-desain-propeller-amp-sistemperporosan-kapal-kontainer-_5a464b13b7d7bc7b7aff906f_pdf.

[10] A.W. B.S, A. Trimulyono, and M. F. Ubaidilah, "Perancangan Kapal Tongkang Sebagai Penyebrangan Masyarakat Di Sungai Bengawan Solo, Desa Jimbung Kabupaten Blora - Desa Kiringan Kabupaten Bojonegoro,” Kapal J. Ilmu Pengetah. dan Teknol. Kelaut., 2012.

[11] S. Palembang, A. Luasunaung, and F. P. T. Pangalila, "Kajian rancang bangun kapal ikan fibreglass multifungsi 13 
GT di galangan kapal CV Cipta Bahari Nusantara Minahasa Sulawesi Utara," J. ILMU DAN Teknol. Perikan. TANGKAP, 2013, doi: 10.35800/jitpt.1.3.2013.1410.

[12] D.A. Prayogo and H. A. Kurniawati, "Desain Deck Cargo Barge sebagai Arena Konser Terapung untuk Daerah Perairan Gili Trawangan - Gili Meno - Gili Air, Lombok.," J. Tek. ITS, vol. 7, no. 2, Feb. 2019, doi: 10.12962/j23373539.v7i2.34876.

[13] I. K. Romadhon, N. Komar, and R. Yulianingsih, "Desain optimal pengolahan sludge padat biogas sebagai bahan baku pelet pakan ikan lele," J. Bioproses Komod. Trop., vol. 1, no. 1, 2013.

[14] A.N. Hasmi et al., "Tinjauan Hambatan pada Rancangan Kapal Tongkang Tanpa Awak Menggunakan Metode Computational Fluid Dynamics - OpenFOAM,” INOVTEK POLBENG, 2019, doi: 10.35314/ip.v9i2.1151.

[15] L. Birk, "Ship Resistance," in Fundamentals of Ship Hydrodynamics, Chichester, UK: John Wiley \& Sons, Ltd, 2019, pp. 10-25.

[16] Indra Kusna Djaya, “Teknik Konstruksi Kapal Baja Jilid 1,” in Jilid1, Jakarta, 2006, p. 26. 